\title{
Genetic and biochemical analysis of a class $C$ non-specific acid phosphatase (NSAP) of Clostridium perfringens
}

\author{
Correspondence \\ Tohru Shimizu \\ tshimizu@med.kanazawa-u.ac.jp
}

Received 27 April 2009

Revised 30 September 2009

Accepted 9 October 2009

\author{
Ruoyu Wang, Kaori Ohtani, Yun Wang, Yonghui Yuan, Sufi Hassan \\ and Tohru Shimizu
}
Department of Bacteriology, Graduate School of Medical Science, Kanazawa University, Kanazawa, Ishikawa 920-8640, Japan

Clostridium perfringens, a Gram-positive anaerobe, is a human pathogen that causes gas gangrene in muscle tissues. Its ability to grow and survive in the host is believed to be due to the production of numerous enzymes that enable the organism to obtain essential nutrients from the host. In this study, CPE0201, a putative acid phosphatase gene deduced by genome analysis, was shown to encode a non-specific acid phosphatase in C. perfringens. Multiple alignments of the amino acid sequence showed that CPE0201 shares two signature motifs that belong to a class $\mathrm{C}$ acid phosphatase family. Expression of CPE0201 was shown to be positively regulated by the global VirR/VirS-VR-RNA regulatory cascade at the transcriptional level. To determine the acid phosphatase activity of the CPE0201-encoded protein, cloning, expression, purification and several biochemical characterizations were carried out. The optimum $\mathrm{pH}$ for activity of the CPE0201 enzyme was 4.8, and its $V_{\max }$ and $K_{\mathrm{m}}$ were $3.08 \mathrm{nmol} \mathrm{ml}{ }^{-1} \mathrm{~min}^{-1}$ and $2.84 \mathrm{mM}$, respectively, with $p$-nitrophenyl phosphate (PNPP) as substrate. A CPE0201 mutant did not grow in a minimal medium containing PNPP, while it showed normal growth when $\mathrm{Na}_{2} \mathrm{HPO}_{4}$ was added to the medium. The enzyme appears to be associated with the surface of the cell, where it may function to acquire inorganic phosphate from organic phosphomonoesters in acidic conditions, which could play an important role in the survival and growth of $C$. perfringens in the host tissue.

\section{INTRODUCTION}

Clostridium perfringens is a Gram-positive anaerobic, sporeforming human pathogen that causes gas gangrene in muscle tissues. Since C. perfringens has been found to possess acid phosphatase activity in acidic conditions, a method to confirm the organism's presence was developed by measuring its acid phosphatase using different phosphatase reagents (Ueno et al., 1970). Since then, improved methods based on acid phosphatase detection have been adapted as routine protocols to detect C. perfringens (Eisgruber et al., 2003). Although the acid phosphatase activity has long been employed as a characteristic of $C$. perfringens that differentiates it from other clostridial species, there are still few reports about the gene(s) that contribute to the acid phosphatase profile.

Bacteria have several enzymes that can dephosphorylate organic compounds, which play various essential or accessory roles in cell physiology. Some of these enzymes can be secreted outside the cell, where they are either released in a soluble form or retained as membrane-bound proteins (Rossolini et al., 1998) to hydrolyse organic

Abbreviations: GST, glutathione S-transferase; NSAP, non-specific acid phosphatase; PNPP, $p$-nitrophenyl phosphate. compounds into inorganic phosphate and organic byproducts that can be transported across the membrane, thus providing the cell with essential nutrients (Beacham, 1979).

Non-specific acid phosphohydrolases or phosphatases (NSAPs) are widely distributed among many Grampositive and Gram-negative bacterial species. NSAPs are considered physiologically important because they either help the cell to utilize organic phosphoesters that cannot cross the cytoplasmic membrane (Beacham, 1979), or have functional importance in gene expression (Carmany et al., 2003). NSAPs are usually grouped into three types (classes A, B and C) on the basis of amino acid sequence relatedness (Thaller et al., 1994, 1995, 1997); they can dephosphorylate a broad array of structurally unrelated substrates and exhibit optimal catalytic activity at acidic to neutral pH values (Rossolini et al., 1998). Class C NSAPs have recently been identified as a subgroup of secreted bacterial lipoproteins endowed with NSAP activity that contain a polypeptide component with a molecular mass of approximately $30 \mathrm{kDa}$ and share conserved sequence motifs (Green et al., 1991; Thaller et al., 1997).

Although the whole genome sequence of $C$. perfringens has been analysed (Shimizu et al., 2002a), the acid 
phosphatase(s) and its gene(s) in C. perfringens still have not been clearly revealed. However, the protein encoded by the CPE0201 gene has amino acid sequence similarities above $40 \%$ with several acid phosphatases of Grampositive bacteria, including Bacillus anthracis (42.3\% identity in 243 aa overlap) (Felts et al., 2006). This fact prompted us to explore the possibility that CPE0201 encodes a protein with acid phosphatase activity. In this study, cloning, expression, purification, biochemical characterizations and phylogenic analysis of CPE0201 and the protein it encodes have been employed to reveal its acid phosphatase properties.

\section{METHODS}

Strains, media and culture conditions. C. perfringens strains 13 (Mahony \& Moore, 1976), TS133 (virR mutant) (Shimizu et al., 1994) and TS140 (vrr mutant) (Shimizu et al., 2002b) were cultured in GAM (Gifu Anaerobic Medium; Nissui, Japan) at $37{ }^{\circ} \mathrm{C}$ under anaerobic conditions, as described previously (Shimizu et al., 1994). A minimal medium that was modified from the original (Riha \& Solberg, 1971) was also used for the culture of $C$. perfringens strains. Escherichia coli strains DH5 $\alpha$ and BL21 were cultured under standard conditions (Sambrook et al., 1989). Plasmid pUC19 was used for general cloning in E. coli, and pGEX-3X was used to construct an expression vector for recombinant proteins. A GSTrap FF column (GE Science) was used to purify a glutathione $S$-transferase (GST) fusion protein expressed in E. coli BL21.

Northern hybridization. Total RNA from C. perfringens was extracted and Northern blotting performed as previously described (Aiba et al., 1981) using an AlkPhos-direct kit and CDP-star Chemiluminescence Reagent (GE Healthcare). DNA probes were prepared by PCR from genomic DNA of $C$. perfringens strain 13 with the appropriate primer sets.

Cloning, expression and purification. To express the predicted NSAP from C. perfringens, the CPE0201 gene was amplified by PCR under standard cycling conditions using primers P201F ( $5^{\prime}$ ccggatccatagaaacttcaaaaattac- $\left.3^{\prime}\right)$ and P201R (5'-ccgaattcttatttaaatgattttatgc- $3^{\prime}$ ), containing BamHI and EcoRI restriction sites, respectively (underlined). Following digestion with BamHI and EcoRI, the amplified DNA fragment was subcloned into pGEX-3X by using the same restriction sites. Finally, the resulting plasmid construct was used to transform competent cells of E. coli BL21. A single colony of E. coli BL21 containing the plasmid pGEX-CPE0201 was inoculated into $5 \mathrm{ml} \mathrm{LB}$ medium containing $50 \mu \mathrm{g}$ ampicillin $\mathrm{ml}^{-1}$ and incubated overnight at $37{ }^{\circ} \mathrm{C}$ with constant aeration. A $1: 100$ dilution of this overnight culture was then inoculated to $200 \mathrm{ml}$ fresh $\mathrm{LB}$ medium. The sample was cultured until the culture reached $\mathrm{OD}_{600}$ 0.6 , at which point IPTG was added to a final concentration of $1 \mathrm{mM}$. The cells were further incubated for $4 \mathrm{~h}$ at $25{ }^{\circ} \mathrm{C}$ after IPTG induction, then harvested by centrifugation at $5000 \mathrm{~g}$ for $10 \mathrm{~min}$. The resulting pellet was resuspended in $10 \mathrm{ml} \mathrm{PBS} \mathrm{(pH} \mathrm{7.4),} \mathrm{and}$ centrifuged at $5000 \mathrm{~g}$ for $10 \mathrm{~min}$. After being washed twice by PBS, the pellet was suspended in $5 \mathrm{ml}$ PBS containing one tablet of Complete Mini Protease Inhibitor Cocktail (Recho). The cells were disrupted by ultrasonic treatment, and unbroken cells and pelletable debris were removed by centrifugation at 15000 r.p.m. for $10 \mathrm{~min}$. Following filtration with a $0.45 \mu \mathrm{m}$ filter, the resulting extract was then applied onto a GSTrap FF column. The GST-CPE0201 fusion protein was purified according to the manufacturer's instructions. The protein concentration was measured by the method of Bradford (1976), using BSA as a standard. The purified protein was checked by
$12 \%$ SDS-PAGE to be of the correct molecular mass and sufficiently pure for the subsequent characterizations.

Enzyme activity assay. The acid phosphatase activity of the GSTCPE0201 product was determined colorimetrically by the release of $p$ nitrophenol from a $6 \mathrm{mM}$ solution of $p$-nitrophenyl phosphate (PNPP) in $100 \mathrm{mM}$ sodium acetate/acetic acid buffer, $\mathrm{pH} 4.8$, containing $5 \mathrm{mM}$ magnesium chloride. Normally the substrate volume was $100 \mu \mathrm{l}$ for a $5 \mu \mathrm{l}$ enzyme sample volume. After incubation at $37^{\circ} \mathrm{C}$ for $30 \mathrm{~min}$, the reaction was stopped by the addition of $100 \mu \mathrm{l} 1 \mathrm{M}$ sodium hydroxide. Absorbance at $405 \mathrm{~nm}$ was measured in a spectrophotometer against a blank of reagents to which the sample was added after the sodium hydroxide. The amounts of $p$ nitrophenol released by the enzyme were determined from an appropriate calibration curve. One unit of enzyme activity was defined as the amount of enzyme able to release $1 \mathrm{mmol} p$ nitrophenol per min under the assay conditions.

Influences of pH and temperature. The thermal stability of the acid phosphatase activity of GST-CPE0201 was determined in a standard assay with the following modifications. Samples of purified enzyme ( $0.005 \mathrm{U}$ of activity) in $100 \mu 100 \mathrm{mM}$ sodium acetate/acetic acid buffer, $\mathrm{pH} 4.8$, containing $5 \mathrm{mM} \mathrm{MgCl}_{2}$, were kept at 4, 25, 37, 45,50 or $60{ }^{\circ} \mathrm{C}$ for $30 \mathrm{~min}$ and returned to $4{ }^{\circ} \mathrm{C}$ for $10 \mathrm{~min}$, then all the samples were assayed for enzymic activity. The $\mathrm{pH}$ profile of acid phosphatase of GST-CPE0201 was determined by assaying $0.005 \mathrm{U}$ of enzyme at $37{ }^{\circ} \mathrm{C}$ for $30 \mathrm{~min}$ in sodium acetate/acetic acid buffer $(\mathrm{pH} 4.4$ to 6.2$)$ at increments of $0.2 \mathrm{pH}$ unit.

Effect of inhibitors on enzyme activity. The following compounds were tested for their inhibitory effect in the standard assay at the concentrations indicated: $20 \mathrm{mM}$ EDTA, $0.47 \mathrm{mM}$ sodium molybdate, $0.1 \%$ SDS, $1.2 \mathrm{mM}$ sodium fluoride $(\mathrm{NaF})$ and $12 \mathrm{mM} \mathrm{L-}$ $(+)$ tartrate.

Construction of CPE0201 mutant. A 450 bp fragment was amplified from the coding region of CPE0201 by PCR using an appropriate primer set. The fragment was cloned into the SmaI site of plasmid pUC118 containing the ermBP (erythromycin-resistance) gene. The plasmid was electroporated into $C$. perfringens strain 13 as described previously (Shimizu et al., 1994), and erythromycinresistant transformants resulting from single-crossover homologous recombination were selected. The mutation of CPE0201 was confirmed by Southern hybridization using a CPE0201 gene probe.

Phylogenetic analysis. Sequence analyses of CPE0201 of $C$. perfringens were done using the BLAST algorithm on the National Center for Biotechnology Information website (http://www.ncbi.nlm. nih.gov/). Sequence data were manipulated with different subroutines from the DNASTAR program. The multiple alignments for sequences were performed by using MEGALIGN in DNASTAR. Amino acid sequences of different acid phosphatases were aligned using MEGA4 software (Tamura et al., 2007) and a phylogenetic tree constructed using the neighbourjoining method (Saitou \& Nei, 1987). The $16 \mathrm{~S}$ rDNA sequences of all bacterial species tested were aligned by the same method.

\section{RESULTS}

\section{Comparative and phylogenetic analyses of CPE0201}

BLAST searches against protein sequence databases in GenBank revealed significant levels (45-33\% sequence identity) of similarity between CPE0201 and several other prokaryotic acid phosphatases. Similarities were found 
with acid phosphatase from Bacillus anthracis (NP_846955, $40 \%$ ), Elizabethkingia meningoseptica (CAA73299, $41 \%$ ), Streptococcus agalactiae (NP_688757, 36\%), Helicobacter pylori (AAQ88280, 33\%), Chlorobium phaeobacteroides (YP_001959498, 32\%), Porphyromonas gingivalis (YP_ 001929139, $38 \%$ ) and Anabaena variabilis (YP_320194, $32 \%)$. Moreover, a considerable level of similarity was also found with some eukaryotic acid phosphatases even though their functions are unknown.

Multiple alignment of the amino acid sequences among the above-mentioned bacterial phosphatases revealed that CPE0201 possesses two motifs in its amino acid sequence. One is (I/V)-(V/A/L)-D-(I/L)-D-E-T-(V/M)-L-X-(N/T)$\mathrm{XX}-\mathrm{Y}$, near the $\mathrm{N}$ terminus, and the other is $(\mathrm{I} / \mathrm{V})-(\mathrm{L} /$ $\mathrm{M}$ )-XX-G-D-(N/T)-L-X-D-F, near the C terminus (Fig. 1). These motifs have been described as the common signature motifs of bacterial class C NSAPs (Thaller et al., 1998). Peptide sequence alignment shows that the signal peptide of CPE0201 shares significant sequence similarity with other typical bacterial lipoproteins having NSAP activity (data not shown). When we determined the acid phosphatase activities in culture supernatant and cell suspension of $C$. perfringens, the activity was only detected in the cell suspension, which implies that the enzyme is not secreted into the supernatant but is associated with the cell membrane or cell wall (data not shown).

The phylogenetic relationships between the CPE0201 protein and representative homologues in other genera of Gram-positive and Gram-negative bacteria are shown in Fig. 2(b). A phylogenetic analysis based on 16S rDNA sequences of those bacteria was also carried out (Fig. 2a). As shown in Fig. 2(a), the 24 bacteria were divided into groups by $16 \mathrm{~S}$ rDNA sequence similarity, which showed good accordance with commonly accepted division theory; however, the groupings based on the acid phosphatase sequences were somewhat different from those based on the 16S rDNA analysis. Especially, CPE0201 seems to have a closer relationship to some homologues in Gram-negative groups than in Gram-positive ones (Fig. 2b). This implies that CPE0201 may not be derived from an ancestral Grampositive bacterium, but may have been acquired by horizontal gene transfer from an unknown ancestor; or the donor might be a Gram-negative organism.

\section{Transcriptional regulation of CPE0201}

In our preliminary experiment using a DNA microarray of C. perfringens strain 13, transcription of CPE0201 seemed to be positively regulated by the VirR/VirS system (Ba-Thein et al., 1996; Shimizu et al., 1994) and its secondary regulator VR-RNA encoded by $\operatorname{vrr}$ (Shimizu et al., 2002b; K. Ohtani and others, unpublished results). The VirR/VirS-VR-RNA regulatory cascade plays important roles in regulating the expression of various toxin genes, which contributes to the pathogenicity of $C$. perfringens. To confirm the microarray data, we performed Northern hybridization experiments using wild-type strain 13, virR mutant strain TS133 and vrr mutant strain TS140. As shown in Fig. 3, the transcription of CPE0201 decreased in TS133 and TS140 at both $2 \mathrm{~h}$ and $3 \mathrm{~h}$ of culture (early to mid-exponential growth), while the expression of CPE0201 was restored by complementation with intact virR/virS and $v$ rr genes in strains TS133/pTS405 and TS140/pTS1031, respectively. The higher level of expression of CPE0201 in the complemented strains than in the wild-type may be due to the overexpression of the virR/virS or vrr gene supplied by the high-copy-number plasmids. The expression pattern of CPE0201 was quite similar to that of $v r r$, encoding VR-RNA, indicating that CPE0201 is under the positive control of the VirR/VirS-VRRNA regulatory cascade in $C$. perfringens.

\section{Expression of CEP0201 in E. coli}

The product of CPE0201 has $94 \%$ identity with that of the CPF0190 protein from C. perfringens ATCC 13124



Fig. 1. Alignment of the amino acid sequence of CPE0201 with the amino acid sequences of various bacterial class $C$ or class B NSAPs. Alignment was maximized by introducing gaps, which are indicated by hyphens. The numbers indicate positions from the $\mathrm{N}$ terminus. A majority consensus sequence (amino acid residues present in at least four of the proteins) is shown in the upper line. The regions corresponding to the fingerprint patterns for class $\mathrm{C}$ acid phosphatases are boxed. 
(a)

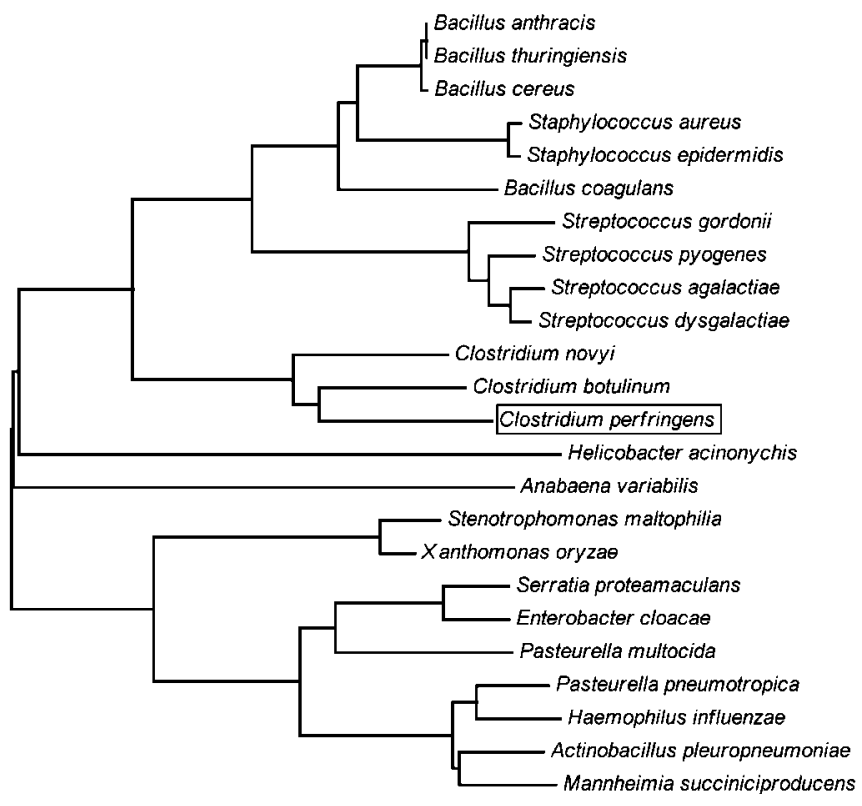

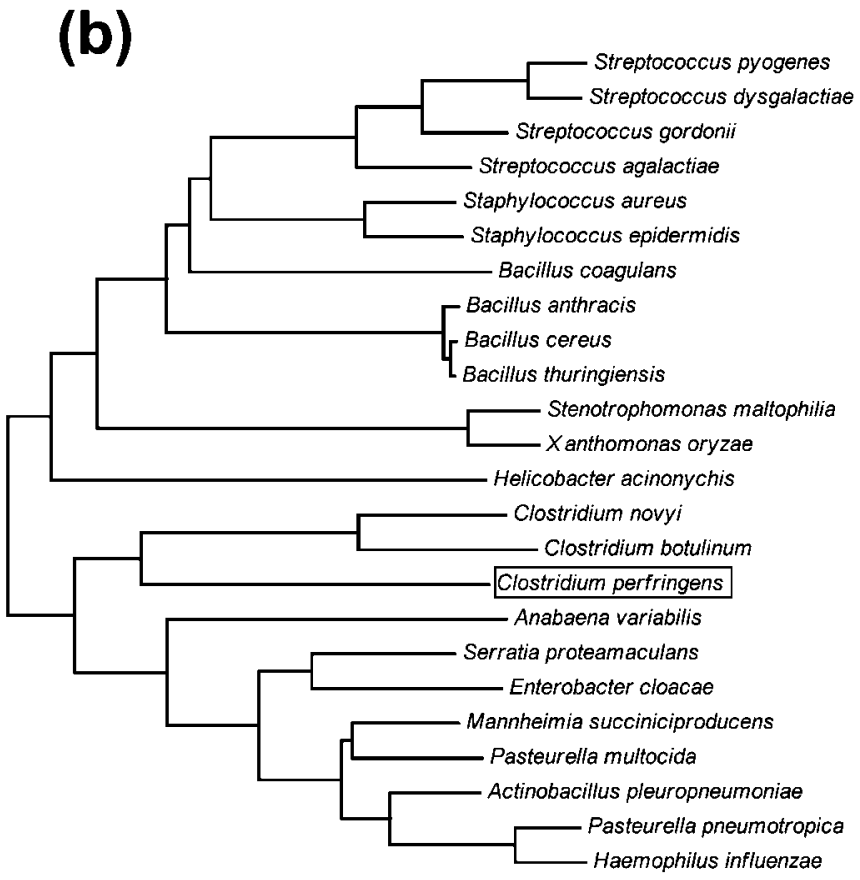

$\longmapsto 0.1$

Fig. 2. Phylogenetic relationship based on (a) $16 \mathrm{~S}$ rDNA sequence and (b) the amino acid sequences of acid phosphatases from various bacteria.

(GenBank accession no. CP000246) and shows 93\% identity with the product of CPR0188 from C. perfringens SM101 (GenBank accession no. CP000312). The CPE0201

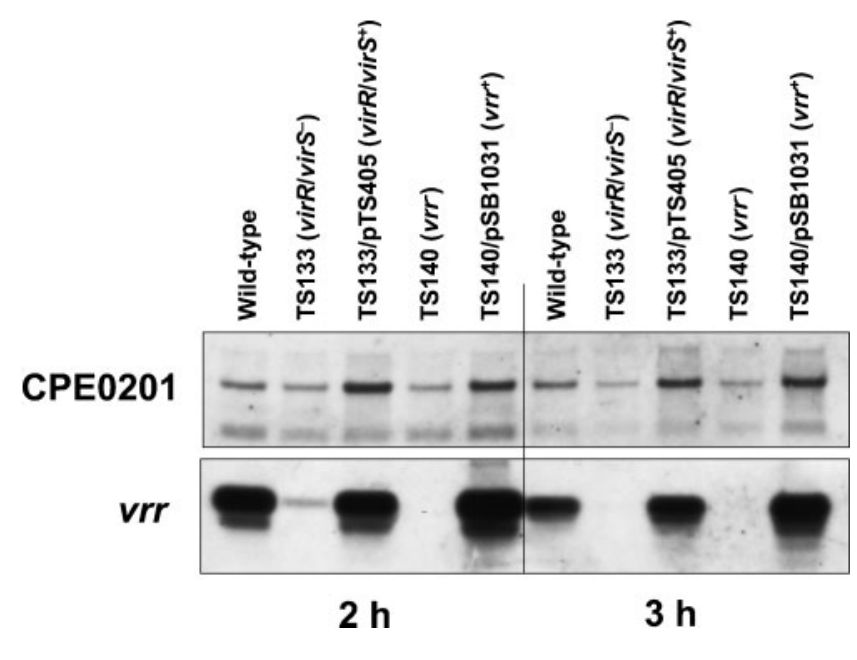

Fig. 3. Northern analysis of the expression of CPE0201. Total RNA was prepared from $2 \mathrm{~h}$ and $3 \mathrm{~h}$ cultures of C. perfringens, and subjected to Northern hybridization. Ten micrograms of total RNA was loaded in each lane (loading was confirmed in ethidiumbromide-stained gel). Gene probes used for hybridization are indicated on the left. Representative data from triplicate experiments that showed similar results are presented. gene encodes a 287 aa protein whose molecular mass is $32.5 \mathrm{kDa}$, which corresponds well with the general molecular mass $(30 \mathrm{kDa})$ of class C NSAPs (Rossolini et al., 1998). To express the protein from CPE0201, we inserted the whole protein-coding region of CPE0201 downstream from the GST tag sequence in plasmid pGEX3X. A heavily Coomassie-stained band of approximately $56 \mathrm{kDa}$ from IPTG-induced cells was found by SDS-PAGE. Purification of the recombinant GST-CPE0201 fusion protein was performed by using a GSTrap affinity column, and the purified product was confirmed by $12 \%$ SDSPAGE (Fig. 4). When we checked the acid phosphatase activity of the GST-CPE0201 fusion protein and the CPE0201 protein with the GST tag removed, there was no obvious difference between the two (data not shown); therefore, the GST-CPE0201 fusion protein was used for all the subsequent experiments.

\section{Acid phosphatase activity of CPE0201 product}

The $K_{\mathrm{m}}$ and $V_{\max }$ of the GST-CPE0201 enzyme for PNPP were determined in $100 \mu \mathrm{l}$ assay mixture containing 0.005 $\mathrm{U}$ of enzyme by measuring the release of $p$-nitrophenol for $30 \mathrm{~min}$ at 12 different substrate concentrations (0.1-10 $\mathrm{mM})$. The rate of substrate hydrolysis was found to follow Michaelis-Menten kinetics at low substrate concentrations $(0.1-3 \mathrm{mM})$. The values obtained for $V_{\max }$ and $K_{\mathrm{m}}$ from a Lineweaver-Burk double reciprocal plot were $3.08 \mathrm{nmol}$ $\mathrm{ml}^{-1} \mathrm{~min}^{-1}$ and $2.84 \mathrm{mM}$, respectively. 


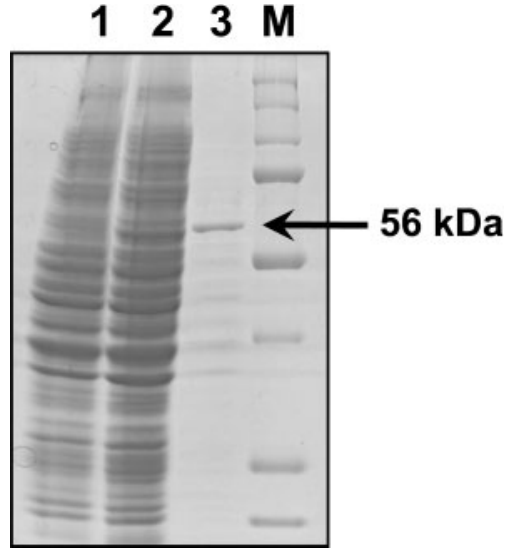

Fig. 4. Expression of GST-CPE0201 fusion protein in E. coli. The SDS-PAGE gel was stained with Coomassie blue. Lanes: 1, E. coli lysate prior to IPTG induction; 2, E. coli lysate after IPTG induction; 3, purified GST-CPE0201 fraction; lane 4, protein molecular mass standards.

\section{Limited thermal stability of CPE0201 product}

To check the thermal stability of the NSAP activity of GSTCPE0201 fusion protein, a sample containing $0.005 \mathrm{U}$ of GST-CPE0201 enzymic activity was heated at different temperatures for $30 \mathrm{~min}$ and then its NSAP activity was measured. This activity was optimum at $40{ }^{\circ} \mathrm{C}$ but dropped rapidly by $78 \%$ at $50{ }^{\circ} \mathrm{C}$ and by $84 \%$ at $55{ }^{\circ} \mathrm{C}$ (data not shown). These data indicate that the NSAP activity of CPE0201 shows limited thermal stability and that the optimum temperature differs from those reported for several other class C NSAPs (Thaller et al., 1998).

\section{Effect of pH on NSAP activity of CPE0201 product}

The NSAP activity of CPE0201 had an optimum pH of 4.8 in the standard assay (Fig. 5). It retained only $27 \%$ of the optimal activity at $\mathrm{pH} 4.4$, although this rapidly increased to $60 \%$ at $\mathrm{pH}$ 4.6. It retained $94 \%$ of optimal activity at $\mathrm{pH} 5.0$, but the activity dramatically dropped to $67 \%$ at $\mathrm{pH}$ 5.2. These data clearly demonstrated the acid phosphatase nature of CPE0201 protein. Unexpectedly, there was an obvious increase in the activity at $\mathrm{pH} 5.6$; it retained $84 \%$ of optimal activity, followed by a rapid decrease at $\mathrm{pH}>5.8$.

\section{Inhibitor assays}

Quantitative in vitro NSAP activity assays (Fig. 6) indicated that $5 \mathrm{mM} \mathrm{MgCl}_{2}$ or $2 \%$ Triton X-100 could enhance the enzyme activity, while the enzyme did not appear to be inhibited by $20 \mathrm{mM}$ EDTA, $0.47 \mathrm{mM}$ sodium molybdate, $12 \mathrm{mM} \mathrm{L}-(+)$ tartrate or $1 \mathrm{mM}$ sodium azide. However, $1.2 \mathrm{mM} \mathrm{NaF}$ or $0.1 \%$ SDS significantly inhibited the enzyme activity.

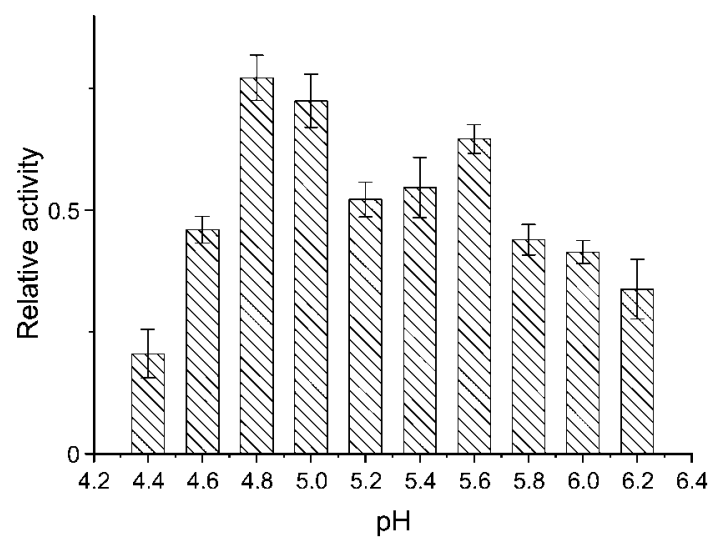

Fig. 5. pH optimum assay of CPE0201 acid phosphatase activity. The $\mathrm{pH}$ profile of acid phosphatase of GST-CPE0201 was determined by assaying $0.005 \mathrm{U}$ of enzyme at $37{ }^{\circ} \mathrm{C}$ for $30 \mathrm{~min}$ in sodium acetate/acetic acid buffer at various $\mathrm{pH}$ values. Means $\pm \mathrm{SD}$ $(n=3)$ are plotted.

\section{Analysis of CPE0201 mutant}

We constructed a CPE0201 mutant (RWM0201) from $C$. perfringens strain 13 by homologous recombination using the internal DNA fragment of CPE0201. Cell suspensions of RWM0201 did not show any acid phosphatase activity (data not shown). To investigate the importance of CPE0201 acid phosphatase in the physiology of $C$. perfringens, we examined the growth of RWM0201 in the presence of PNPP or inorganic phosphate in a minimal

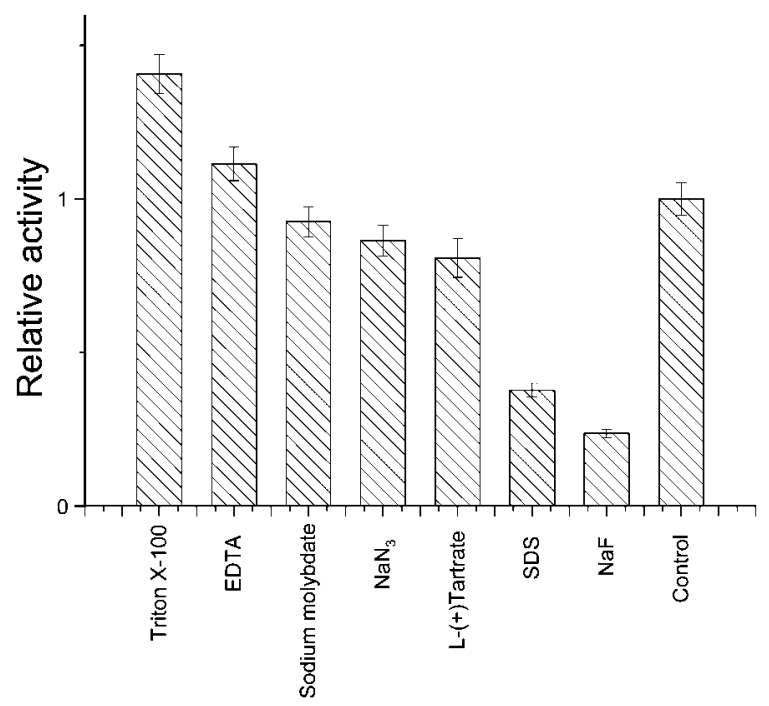

Fig. 6. Effects of various inhibitors on CPE0201 acid phosphatase activity. Activity was determined in the standard assay at $37{ }^{\circ} \mathrm{C}$, with $0.005 \mathrm{U}$ of enzyme, $6 \mathrm{mM}$ PNPP and the corresponding inhibitor; values (means $\pm \mathrm{SD}, n=3$ ) are shown relative to a control with no inhibitor. 
medium lacking other sources of phosphate (Fig. 7). In the minimal medium containing $1 \mathrm{mM} \mathrm{Na}_{2} \mathrm{HPO}_{4}$, both strain 13 (wild-type) and RWM0201 grew similarly, while RWM0201 could not grow in the medium containing PNPP only. These data indicate that the CPE0201 enzyme is important in degrading organic phosphomonoesters into inorganic phosphate in environments where no inorganic phosphate is available and that CPE0201 is the only gene encoding acid phosphatase in $C$. perfringens.

\section{Distribution of CPE0201 among C. perfringens strains}

To investigate the importance of CPE0201 in C. perfringens, we checked the existence of the gene in other strains of $C$. perfringens stocked in our laboratory (four type A strains, two strains each from type B, type C, type D and type E). A PCR-based analysis using the CPE0201 primer set detected identical DNA fragments in all 12 strains (data not shown). These data indicate that CPE0201 is highly conserved among various $C$. perfringens strains, which may imply the importance of acid phosphatase in the physiology of $C$. perfringens.

\section{DISCUSSION}

Numerous extracellular toxins and enzymes of C. perfringens are believed to be involved in the ability to cause gas gangrene (clostridial myonecrosis) in humans, including alpha-, theta- and kappa-toxins (Rood, 1998). The role of the acid phosphatase encoded by CPE0201 in the physiology of the organism is also of great interest to us because, in present study, the transcription of CPE0201 was shown to be regulated by the VirR/VirS-VR-RNA cascade, which also involves the genes for alpha-, kappa- and thetatoxins (Ba-Thein et al., 1996). The genetic mechanism of the global regulation by VR-RNA is still unclear, since the genes regulated by VR-RNA share no common DNA motifs in their promoter or leader regions. Similarly, there was no apparent DNA sequence in the promoter region of CPE0201 that was similar to those of other VR-RNAregulated genes.

Classification of bacterial phosphatases was initially based on the biochemical and biophysical properties of the enzymes, such as $\mathrm{pH}$ optimum (acid, neutral or alkaline), substrate profile (non-specific vs specific for certain substrates) and molecular size (high vs low molecular mass) (Rossolini et al., 1998). As numerous nucleotide sequence data became available, phosphatases were grouped into different molecular families according to similarity at the level of the primary structure. In this study, multiple alignments of the deduced amino acid sequence of the CPE0201 protein against nonredundant protein databases in GenBank showed that CPE0201 shares two conserved signature motifs belonging to an acid phosphatase family. It shows the greatest homology to several acid phosphatases of class C bacterial NSAPs. Furthermore, we have shown here that the CPE0201 protein has typical NSAP biochemical properties. To our knowledge, CPE0201 is the first clostridial acid phosphatase to be identified and characterized at a biochemical level. Based on phylogenetic and structural considerations, we propose that the CPE0201 should be defined as a member of the class C NSAPs, a broad group of phosphatases consisting of secreted proteins that function in an acidic-to-neutral $\mathrm{pH}$ range and that use a wide variety of organic phosphoesters as substrates (Rossolini et al., 1998). It is possible that in the normal habitat of $C$. perfringens, the CPE0201 acid phosphatase may play a physiological role as a scavenger in rendering organic phosphomonoesters available for transport into the cell; otherwise, they cannot pass through the cytoplasmic membrane (Dissing \& Uerkvitz, 2006).
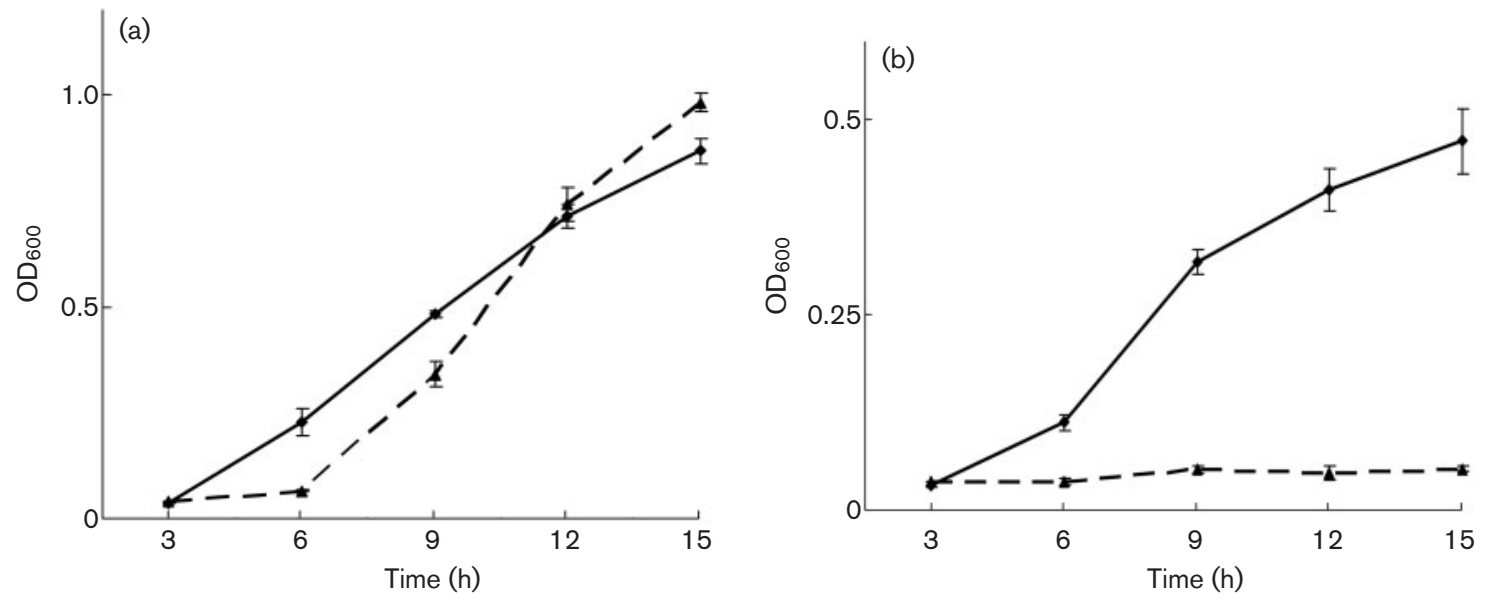

Fig. 7. Growth curves of the wild-type strain ( $\boldsymbol{\nabla}$, solid lines) and the CPE0201 mutant RWM0201 ( $\mathbf{\Delta}$, dashed lines) of C. perfringens at $37{ }^{\circ} \mathrm{C}$, in modified minimal medium with $1 \mathrm{mM} \mathrm{Na} \mathrm{HPO}_{4}$ (a) or $0.1 \mathrm{mM}$ PNPP (b). 
Based on a functional search against all ORFs in the whole genome of C. perfringens strain 13, CPE0201 is believed to represent the only gene to encode an NSAP. Generally, acid phosphatases of Gram-positive bacteria are bound to the cell surface (Okabayashi et al., 1974) or cytoplasmic membrane (Poirier \& Holt, 1983). CPE0201 appears to be the only surface-associated acid phosphatase of $C$. perfringens. However, the precise location of CPE0201 at a subcellular level should be further investigated. Whether or not the enzyme is produced in the human host suffering from C. perfringens infection is presently unknown, and therefore its exact pathological importance to humans should be examined.

\section{ACKNOWLEDGEMENTS}

This work was supported by a KAKENHI (Grant-in-Aid for Scientific Research) on the Priority Area 'Applied Genomics' from the Ministry of Education, Culture, Sports, Science and Technology of Japan.

\section{REFERENCES}

Aiba, H., Adhya, S. \& de Crombrugghe, B. (1981). Evidence for two functional gal promoters in intact Escherichia coli cells. J Biol Chem 256, 11905-11910.

Ba-Thein, W., Lyristis, M., Ohtani, K., Nisbet, I. T., Hayashi, H., Rood, J. I. \& Shimizu, T. (1996). The virR/virS locus regulates the transcription of genes encoding extracellular toxin production in Clostridium perfringens. J Bacteriol 178, 2514-2520.

Beacham, I. R. (1979). Periplasmic enzymes in gram-negative bacteria. Int J Biochem 10, 877-883.

Bradford, M. M. (1976). A rapid and sensitive method for the quantitation of microgram quantities of protein utilizing the principle of protein-dye binding. Anal Biochem 72, 248-254.

Carmany, D. O., Hollingsworth, K. \& McCleary, W. R. (2003). Genetic and biochemical studies of phosphatase activity of PhoR. J Bacteriol 185, 1112-1115.

Dissing, K. \& Uerkvitz, W. (2006). Class B nonspecific acid phosphatase from Salmonella typhimurium LT2: phosphotransferase activity, stability and thiol group reactivity. Enzyme Microb Technol 38, 683-688.

Eisgruber, H., Geppert, P., Sperner, B. \& Stolle, A. (2003). Evaluation of different methods for the detection of Clostridium perfringens phosphatases. Int J Food Microbiol 82, 81-86.

Felts, R. L., Reilly, T. J., Calcutt, M. J. \& Tanner, J. J. (2006). Cloning, purification and crystallization of Bacillus anthracis class $\mathrm{C}$ acid phosphatase. Acta Crystallogr Sect F Struct Biol Cryst Commun 62, 705-708.

Green, B. A., Farley, J. E., Quinn-Dey, T., Deich, R. A. \& Zlotnick, G. W. (1991). The $e(\mathrm{P} 4)$ outer membrane protein of Haemophilus influenzae: biologic activity of anti-e serum and cloning and sequencing of the structural gene. Infect Immun 59, 3191-3198.

Mahony, D. E. \& Moore, T. I. (1976). Stable L-forms of Clostridium perfringens and their growth on glass surfaces. Can J Microbiol 22, 953-959.
Okabayashi, K., Futai, M. \& Mizuno, D. (1974). Localization of acid and alkaline phosphatases in Staphylococcus aureus. Jpn J Microbiol 18, 287-294.

Poirier, T. P. \& Holt, S. C. (1983). Acid and alkaline phosphatases of Capnocytophaga species. I. Production and cytological localization of the enzymes. Can J Microbiol 29, 1350-1360.

Riha, W. E., Jr \& Solberg, M. (1971). Chemically defined medium for the growth of Clostridium perfringens. Appl Microbiol 22, 738-739.

Rood, J. I. (1998). Virulence genes of Clostridium perfringens. Annu Rev Microbiol 52, 333-360.

Rossolini, G. M., Schippa, S., Riccio, M. L., Berlutti, F., Macaskie, L. E. \& Thaller, M. C. (1998). Bacterial nonspecific acid phosphohydrolases: physiology, evolution and use as tools in microbial biotechnology. Cell Mol Life Sci 54, 833-850.

Saitou, N. \& Nei, M. (1987). The neighbor-joining method: a new method for reconstructing phylogenetic trees. Mol Biol Evol 4, 406425.

Sambrook, J., Fritsch, E. F. \& Maniatis, T. (1989). Molecular Cloning: a Laboratory Manual, 2nd edn. Cold Spring Harbor, NY: Cold Spring Harbor Laboratory.

Shimizu, T., Ba-Thein, W., Tamaki, M. \& Hayashi, H. (1994). The virR gene, a member of a class of two-component response regulators, regulates the production of perfringolysin $\mathrm{O}$, collagenase, and hemagglutinin in Clostridium perfringens. J Bacteriol 176, 1616-1623.

Shimizu, T., Ohtani, K., Hirakawa, H., Ohshima, K., Yamashita, A., Shiba, T., Ogasawara, N., Hattori, M., Kuhara, S. \& Hayashi, H. (2002a). Complete genome sequence of Clostridium perfringens, an anaerobic flesh-eater. Proc Natl Acad Sci U S A 99, 996-1001.

Shimizu, T., Yaguchi, H., Ohtani, K., Banu, S. \& Hayashi, H. (2002b). Clostridial VirR/VirS regulon involves a regulatory RNA molecule for expression of toxins. Mol Microbiol 43, 257-265.

Tamura, K., Dudley, J., Nei, M. \& Kumar, S. (2007). MEGA4: Molecular Evolutionary Genetics Analysis (MEGA) software version 4.0. Mol Biol Evol 24, 1596-1599.

Thaller, M. C., Berlutti, F., Schippa, S., Lombardi, G. \& Rossolini, G. M. (1994). Characterization and sequence of PhoC, the principal phosphate-irrepressible acid phosphatase of Morganella morganii. Microbiology 140, 1341-1350.

Thaller, M. C., Lombardi, G., Berlutti, F., Schippa, S. \& Rossolini, G. M. (1995). Cloning and characterization of the NapA acid phosphatase/phosphotransferase of Morganella morganii: identification of a new family of bacterial acid-phosphatase-encoding genes. Microbiology 141, 147-154.

Thaller, M. C., Schippa, S., Bonci, A., Cresti, S. \& Rossolini, G. M. (1997). Identification of the gene (aphA) encoding the class B acid phosphatase/phosphotransferase of Escherichia coli MG1655 and characterization of its product. FEMS Microbiol Lett 146, 191-198.

Thaller, M. C., Berlutti, F., Schippa, S., Selan, L. \& Rossolini, G. M. (1998). Bacterial acid phosphatase gene fusions useful as targets for cloning-dependent insertional inactivation. Biotechnol Prog 14, 241247.

Ueno, K., Fujii, H., Marui, T., Takahashi, J. \& Sugitani, T. (1970). Acid phosphatase in Clostridium perfringens. A new rapid and simple identification method. Jpn J Microbiol 14, 171-173.

Edited by: T. Msadek 